\title{
IL-32: A Novel Pluripotent Inflammatory Interleukin, towards Gastric Inflammation, Gastric Cancer, and Chronic Rhino Sinusitis
}

\author{
Muhammad Babar Khawar, ${ }^{1}$ Muddasir Hassan Abbasi, ${ }^{1,2}$ and Nadeem Sheikh ${ }^{1}$ \\ ${ }^{1}$ Cell and Molecular Biology Lab, Department of Zoology, University of the Punjab, Lahore 54590, Pakistan \\ ${ }^{2}$ Department of Zoology, Government College of Science, Wahdat Road, Lahore, Pakistan \\ Correspondence should be addressed to Nadeem Sheikh; s_nadeem77@yahoo.com
}

Received 24 December 2015; Revised 23 February 2016; Accepted 20 March 2016

Academic Editor: Yona Keisari

Copyright (C) 2016 Muhammad Babar Khawar et al. This is an open access article distributed under the Creative Commons Attribution License, which permits unrestricted use, distribution, and reproduction in any medium, provided the original work is properly cited.

\begin{abstract}
A vast variety of nonstructural proteins have been studied for their key roles and involvement in a number of biological phenomenona. Interleukin-32 is a novel cytokine whose presence has been confirmed in most of the mammals except rodents. The IL-32 gene was identified on human chromosome 16 p13.3. The gene has eight exons and nine splice variants, namely, IL-32 $\alpha$, IL-32 $\beta$,

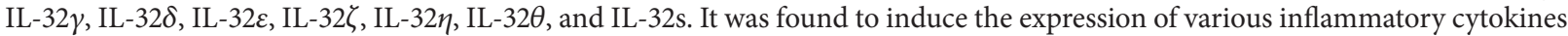
including TNF- $\alpha$, IL-6, and IL-1 $\beta$ as well as macrophage inflammatory protein-2 (MIP-2) and has been reported previously to be involved in the pathogenesis and progression of a number of inflammatory disorders, namely, inflammatory bowel disease (IBD), gastric inflammation and cancer, rheumatoid arthritis, and chronic obstructive pulmonary disease (COPD). In the current review, we have highlighted the involvement of IL-32 in gastric cancer, gastric inflammation, and chronic rhinosinusitis. We have also tried to explore various mechanisms suspected to induce the expression of this extraordinary cytokine as well as various mechanisms of action employed by IL-32 during the mediation and progression of the above said problems.
\end{abstract}

\section{Introduction}

Cytokines are low molecular weight polypeptides/proteins involved in maintenance of homeostatic function in the body. They are pleotropic and are either autocrine (itself), paracrine (nearby cells), or endocrine (distant target cells) in nature $[1,2]$ and can be classified on the basis of their origin and biological activity. Cytokines generally include lymphokines, monokines, chemokines, and interleukins. The aim of the current review is to emphasize the existing therapeutic potential and future perspective of interleukin-32 (IL-32). The pluripotency and remarkable roles of this interleukin have encouraged their vast application in the field of medical biology.

\section{Review}

Interleukin-32 (IL-32), a recently described novel proinflammatory cytokine primarily expressed by natural killer
(NK) cells, monocytes, epithelial cell lines, and T-cells, has gained popularity because of its involvement in many crucial biological phenomena [3-6]. Since its discovery in 1992, IL32 was named natural killer cell transcript 4 (NK4) because of its selective expression in IL-2 activated NK cells [7]. The potential biological activities of IL-32 remained veiled until 2005 when Kim and coworkers (2005) reported its involvement in inducing some other inflammatory cytokines, namely, IL-8 and TNF- $\alpha$ [4]. Because of this reason a new name, IL-32, was assigned to NK4.

One problem that still remains associated with IL-32 is the identification of cell surface receptor of IL-32. The structure of IL-32 is unique in this regard as it lacks any specific cell surface receptor involved in signal transduction exterior to the cell, and it is suspected to exert its influence through some intracellular molecular interactions [8-11]. Studies have been carried out for extracellular activities of IL-32 which have suggested the integrin signaling to be involved in mediating the effects of IL-32 [12]. Recently, 
IL-32, via interactions with some other molecules, has been reported to be involved in various intracellular signaling. IL$32 \alpha$ being intracellularly mediated interacts with not only paxillin, protein kinase $\mathrm{c}$ (PKC), and integrin, but also focal adhesion kinase 1 (FAK 1). Interaction with PKC leads to modulation of IL- 6 in myelomonocytes actively expressing IL-32 $\alpha[9,13]$. Recent studies have revealed the interactions among different isoforms of IL-32 $[10,14]$ as well as with other transcriptional regulators and various proteins $[9,11]$.

One thing that is unique to this cytokine is that a significant amount of recombinant IL-32 protein is required to activate specific cells compared to that of other cytokines. That is the reason it does not seem to be a normal cytokine and does not belong to any of the known cytokine families [4].

One thing that acts as hurdle in the development of IL32 research and in vivo studies is that IL-32 gene has not been identified in rodents [15]. So, most of the studies that aimed to understand the biological activities and functioning of different isoforms have been carried out using Tg mice [16].

IL-32 gene was found to be located on human chromosome 16p13.3 and was reported to exist in nine different isoforms by mRNA alternative splicing including IL-32 $\alpha$, IL$32 \beta$, IL-32 $\gamma$, IL-32 $\delta$, IL-32 $\varepsilon$, IL-32 $\zeta$, IL-32 $\eta$, IL-32 $\theta$, and IL$32 \mathrm{~s}[4,14,17]$, tagged with specific activities and properties $[10,14,18-20]$. For example, IL-32 $\beta$ is involved in increasing the immune cell adhesion to the activated endothelial cells [21]. Similarly, IL-32 $\gamma$, which is biologically the most active one, has shown a potent antiviral role against a number of familiar viruses, namely, vesicular stomatitis virus (VSV), HIV, influenza A virus (IAV), and herpes simplex virus 2 (HSV-2) [22-26]. IL-32 has been proved as a pluripotent cytokine. Kang et al. (2013) previously reported the upregulation of IL-10 by IL-32 $\beta$ through $\mathrm{PKC} \delta$ pathway [11]. In another study, Kang et al. (2013) studied the effects of other isoforms of IL-32 in IL-10 upregulation. They reported inhibitory mechanism of IL-32 $\delta$ and its involvement in the decrease of IL-10 production. IL-32 $\delta$ interacts with IL-32 $\beta$ and showed its inhibitory effects by suppressing the binding of IL-32 $\beta$ to $\mathrm{PKC} \delta$. Their data was indicative of regulation of IL-32 by its own isoforms [10].

Recently, interaction of IL-32 $\theta$ with chemokine C-C motif ligand 5 (CCL5) has also been reported. Bak et al. (2014) reported that IL-32 $\theta$ by mediating the phosphorylation of STAT3 on Ser727 downregulates CCL5 expression by interacting with $\mathrm{PKC} \delta$ and renders this chemokine transcriptionally inactive. This report suggested the role of IL-32 $\theta$ as an intracellular modulator of inflammation [27].

Recently, Kim et al. (2014) reported the involvement of IL-32 $\theta$ in the reduction of leukemia. This isoform compared to IL-32 $\beta$ was reported to downregulate the process of differentiation of a monocytes cell line to macrophages induced by phorbol 12-myristate 13-acetate (PMA) treatment. Expression of this cytokine not only inhibited the adhesion capability of THP-1 cells (monocytic leukemia cells) either to vascular endothelial cells or to culture plates but also inhibited morphological changes. Even after the treatment of PMA in THP-1/IL-32 $\theta$ cells, IL-32 $\theta$ was found to inhibit the expression of various macrophage markers, namely, CD11b,
CD18, and CD36. Furthermore, in THP-1/IL-32 $\theta$ cells, there was found a reduction in the expression of PU.1 as compared to THP-1/IL-32 $\beta$ and wild type cells. Hence, IL-32 $\theta$ was reported to inhibit monocytic differentiation by reducing the PU.1 expression [28].

In another study on acute myeloid leukemia (AML), Kim et al. (2015) described the effects of IL-32 $\theta$ on TNF- $\alpha$ production. About $38 \%$ of total subjects of AML were found to express endogenous IL-32 $\theta$, compared to healthy subjects who did not even express it. To measure serum level of various proinflammatory cytokines, namely, TNF- $\alpha$, IL- $1 \beta$, and IL6 , plasma was assorted into two groups with or without IL$32 \theta$. IL-32 $\theta$ expressing group showed a decrease in TNF- $\alpha$ production compared to group without IL-32 $\theta$. It was also reported that, in an IL-32 $\theta$ stable expression system, IL-32 $\theta$ attenuated the PMA-induced TNF- $\alpha$ production in leukemia cell lines [29]. Bak et al. (2016) reported an inhibition of invasion and migration of colon cancer cells both in vitro and in vivo by ectopic expression of IL-32 $\theta$. In HT29 colon cancer cells, IL-32 $\theta$ attenuated the invasive and migratory potential by suppressing the epithelial-mesenchymal transition (EMT). Furthermore, this interleukin is involved in alterations of a number of properties of cancer stem cells (CSCs) by inhibiting the STAT3-ZEB1 pathway and could be a tumor suppressor [30].

Previous studies carried out on the expression of IL-32 have revealed that a variety of stimuli stimulate IL-32 genes; as a result, IL- $32 \alpha$ is expressed in various inflammatory cells, namely, NK cells, T-cells, peripheral blood mononuclear cells (PBMCs), and monocytes as well as some nonimmune cells, namely, endothelial cells, fibroblasts, and keratinocytes [7, 3133].

All isoforms of IL-32 as well as IL- $1 \beta$ do not possess a classic signal peptide. Hence, because of this reason it is secreted in the least quantities and supernatant does not contain any detectable amount of IL-32. On the contrary all the measurable IL-32 was found in cell lysates [17, 26, 31, 34]. As these secreted proteins are not easily purified and their structure has not been completely evaluated, no structural data have been reported.

Initially, NK4 cDNA was not observed expressing as recombinant protein because it was found to contain a signal peptide sequence that lacks any transmembrane domain [7]. So, the NK4 coding protein was assumed to be a secreted protein. The newly discovered isoforms do not possess a putative signal peptide; therefore, the role of this interleukin still remains controversial whether it affects the cells from inside or outside [17]. Kim et al. (2005) reported that IL-32 secreted from the cells is very small in amount and difficult to detect compared to the amounts present in cytosol [4].

IL-32 is reported to be involved in the stimulation and production of macrophage inflammatory protein-2 (MIP-2) as well as various chemokines and inflammatory cytokines, namely, IL-1 $\beta$, IL-6, IL-8, and TNF- $\alpha$ [4, 35-37]; hence, it acts as a key player in innate and adaptive immunity in vitro [3]. IL- $1 \beta, \mathrm{TNF}-\alpha$, IL-2, or IFN- $\gamma$ is found to be involved in the production of this interleukin in epithelial cells and blood monocytes $[4,7,38]$. It is pleiotropic in action and controls cell differentiation [35, 39, 40], stimulation 


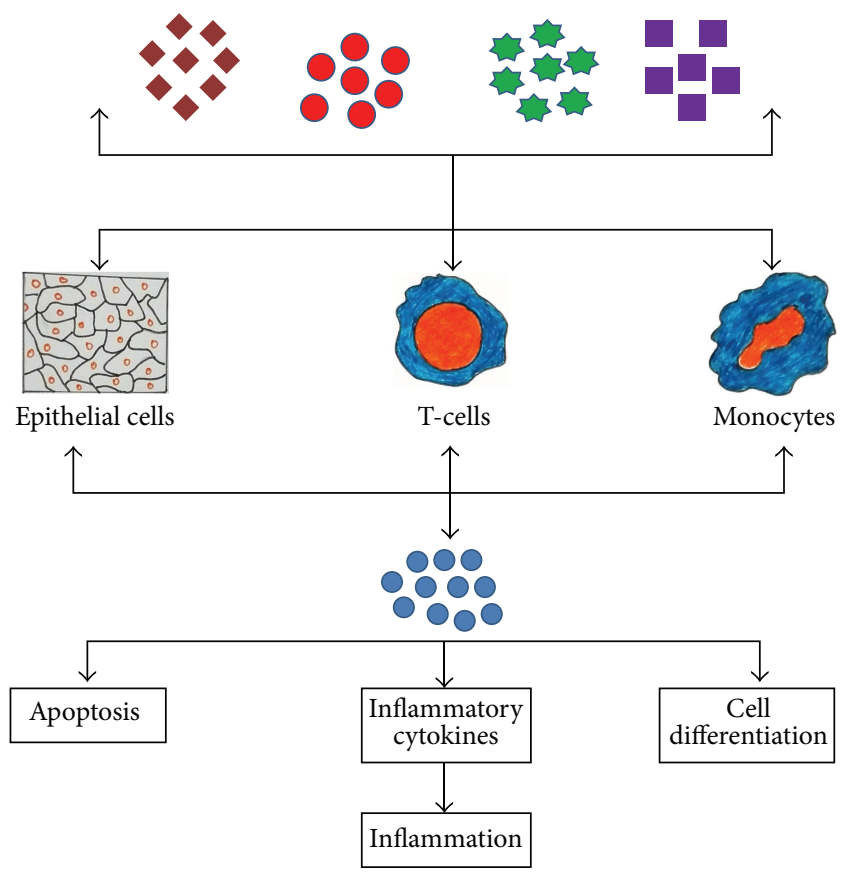

\begin{tabular}{ll} 
TNF- $\alpha$ & \multicolumn{3}{|c}{ IL-1 $\beta$} \\
IL-2 & IFN- $\gamma$
\end{tabular}

FIGURE 1: Mechanism of synthesis of IL-32 by different body cells (T-cells, epithelial cells, and blood monocytes) induced by various cytokines. IL-32 after its secretion affects a number of biological activities, namely, apoptosis and cell differentiation as well as mediation of inflammation.

of pro- or anti-inflammatory cytokines [41-43], and cell death, especially apoptosis $[17,32]$, and is pleiotropic in the pathogenesis of various disorders, like infectious, cancerous, inflammatory, and allergic diseases (Figure 1).

Role of this cytokine in rheumatoid arthritis, chronic obstructive pulmonary disease, and inflammatory bowel disease was reviewed previously by Khawar et al. (2015) [44]. The purpose of the current review is to analyze its role related to gastric inflammation, gastric cancer, and some other related diseased conditions.

\section{IL-32 in Gastric Inflammation and Gastric Cancer}

Globally gastric cancer is one of the leading causes of cancer-related mortality and is the 4th most common type of cancer and 2nd among all mortalities [45]. In the year 2010, in Taiwan, only gastric cancer was blamed as the 6th leading cause of cancer-related deaths [46]. Prognosis of this disease is very poor due to lack of sufficient information, so the only solution left behind is surgery. So, there is an intensive need to identify the biomarkers and elaboration of the exact mechanism involved in the pathogenicity of this disease. Similarly, some novel therapeutic remedies will be worthwhile [47].

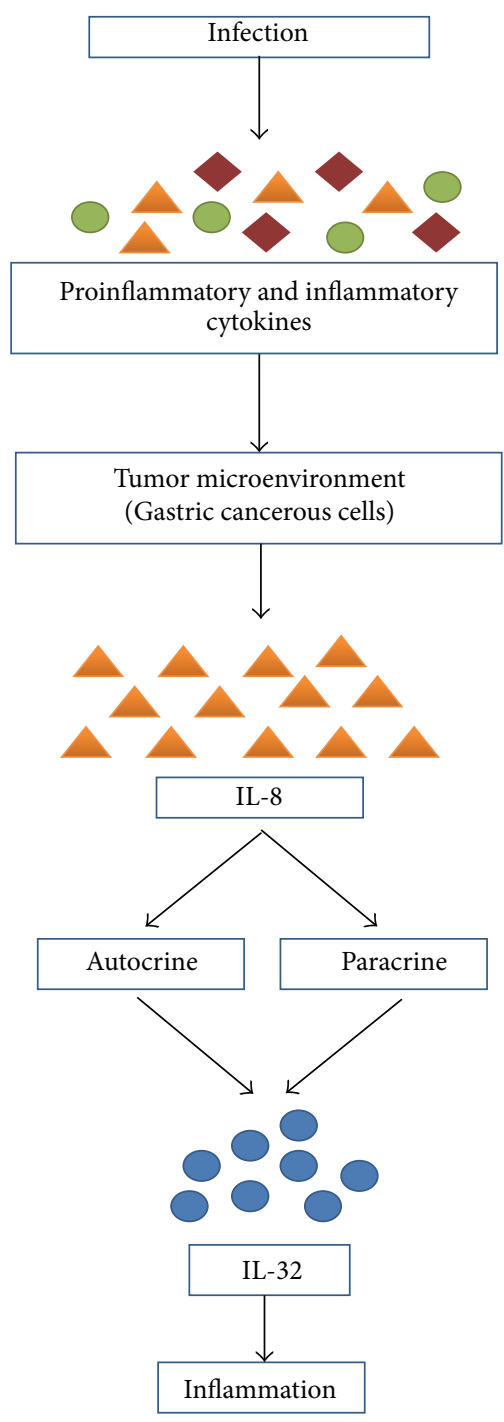

FIGURE 2: How gastric cancerous cells lead to inflammation mediated by IL-32. Infections in the body set in motion the synthesis and secretion of a variety of proinflammatory and inflammatory cytokines which results in the development of tumor microenvironment in gastric cancerous cells that are continuously involved in the production of IL- 8 which exerts its biological influence by initiating the production of IL-32 which is blamed to be involved in gastric inflammation.

In response to infection, certain inflammatory cytokines are released which influence tumor production in a variety of ways. For example, gastric cancer cells secrete IL- 8 which in the presence of a high level of IL-32 has been reported in mucosa of gastric cancer compared to nontumor mucosa [48] (Figure 2).

The exact mechanism involved in induction is overexpression of IL-32 which is still controversial but chromosomal region $16 \mathrm{p} 13.3$ was reported to be amplified and transcribed in cancer of small intestine and breast $[49,50]$. Tsai et al. (2014) reported an enhanced expression of IL-32 in patients of gastric cancer which was found to be positively correlated 
with fierceness of the cancer. Ectopic expression of IL32 by employing phosphor-AKT/phospho-glycogen synthase kinase $3 \beta$ /active $\beta$-catenin and hypoxia-inducible factor $1 \alpha$ (HIF-1 $\alpha$ ) signaling pathways leads to increased invasion and cell migration as well as causing an elongated morphology by inducing the expression of MMP9, matrix metalloproteinase 2 (MMP2), VEGF, and IL-8 as well. On the contrary, by depletion of IL-32 in gastric cancer cells, all of these above-said activities were found to be reversed and lung colonization in vivo was found to be significantly decreased [46].

Similarly, expression of IL-32 in human stomach cancer has been studied with monoclonal antibody KU32-52 and a polyclonal antibody employing sandwich ELISA by Seo et al. (2008). The results of this ELISA were found not to react with other different cytokines, namely, hIL-2, hIL-6, hTNF- $\alpha$, hIL8 , hIL-10, hIL-18, hIL-1 $\alpha$, and hIL-1 $\beta$. Intra-assay coefficients and interassay coefficients variations were found as $18.5 \%-$ $4.6 \%(n=10)$ and $23 \%-9 \%(n=10)$, respectively. Average serum level of IL-32 was found significantly higher in patients of stomach cancer $(189 \mathrm{pg} / \mathrm{mL}, n=16)$ compared to healthy control $(109 \mathrm{pg} / \mathrm{mL}, n=12)$ [48].

\section{Microbial Pathogen Factors (H. pylori)}

Inflammation and cancer related to microbial infections have been studied extensively in previous years. Robin Warren and Marshall (1983) isolated for the first time the causative agent $H$. pylori from gastritis patients [51]. Infection caused by $H$. pylori often contributes to inflammation and cancer of GIT which is one of the leading causes of death due to cancer related mortality globally [52-54]. The pathogenesis of gastric insults involves a cluster of more than 30 genes more commonly known as the cag pathogenicity island (PAI) of $H$. pylori which has been associated with gastric mucosaassociated lymphoid tissue (MALT) lymphoma, gastric cancer, and some other gastric diseases $[55,56]$.

In infected epithelial cells, $H$. pylori cagPAI activates the NF- $\kappa \mathrm{B}$ and mitogen-activated protein kinase (MAPK) signaling pathways. NF- $\kappa \mathrm{B}$ regulates various cellular responses, namely, inflammation, cell death, cell proliferation, and cell survival as well as heightening the production of other inflammatory cytokines such as interleukin- $1 \beta$ (IL-1 $\beta$ ), IL-8, and tumor necrosis factor alpha (TNF- $\alpha$ ). IL-8, an inflammatory cytokine, plays an important role in gastritis and gastric carcinogenesis [57-59] and induced gastric inflammation by introducing neutrophils infiltration. Increased risk of atrophic gastritis and gastric cancer in Japanese population is because of upregulation of IL-8 as a result of single polymorphism in the gene of IL-8 [60]. Polymorphisms of other inflammatory cytokines, namely, IL- $1 \beta$ and TNF- $\alpha$ gene, also have been linked with gastritis and gastric cancer $[61,62]$.

Sakitani et al. (2012) reported an elevation in the level of expression of IL-32 in human gastritis and gastric cancer tissues. Results of the following study suggested the basic role of IL-32 in gastric inflammation caused by $H$. pylori which induces NF- $\kappa \mathrm{B}$ activation in a cagPAI-dependent manner required for IL-32 upregulation in gastric tissues.
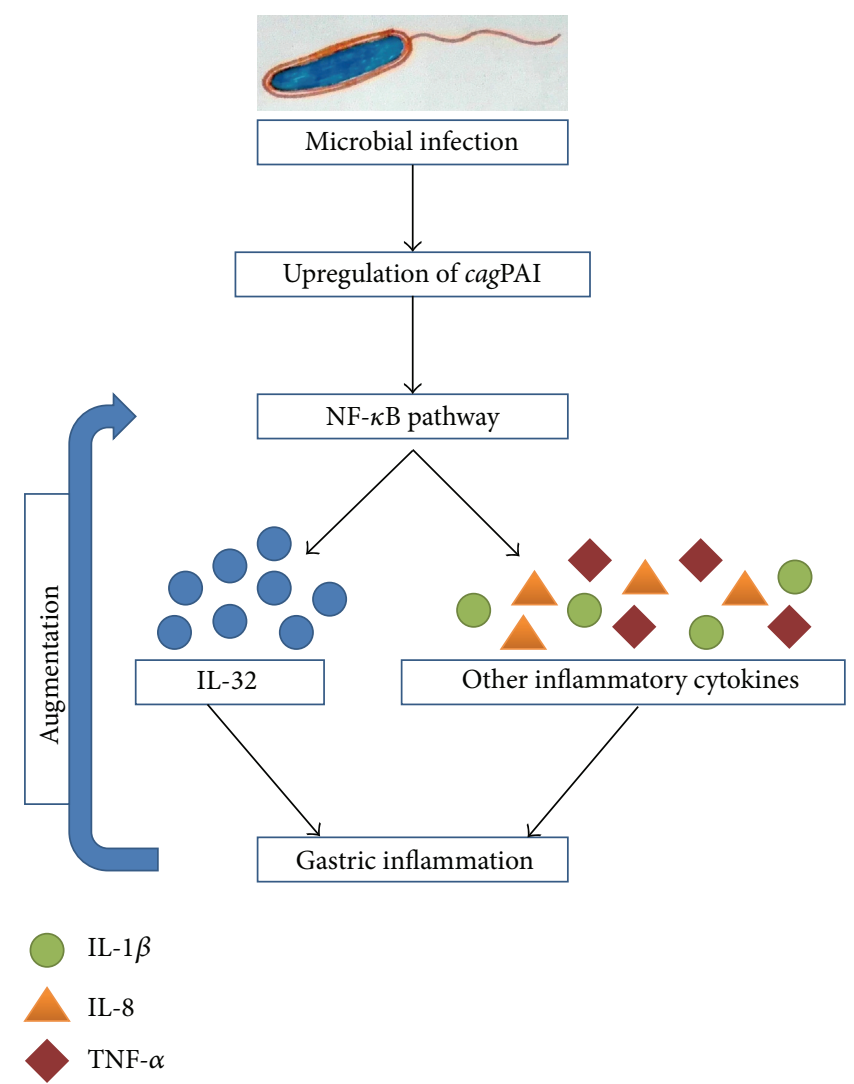

FIGURE 3: Microbial infection induced expression of IL-32 results in gastric inflammation. Microbial infection ( $H$. pylori) leads to the upregulation of cagPAI cluster of genes which through the activation of NF- $\kappa$ B pathway results in the synthesis of IL-32 and some other potent inflammatory cytokines (IL-1, IL-8, and TNF- $\alpha$ ) that results in gastric inflammation. The resulting inflammation selfaugments the activation of NF- $\kappa$ B pathway which further aggravates the situation.

Intracellular IL-32 produced in such a way augments NF- $\kappa \mathrm{B}$ activity and cytokine production, accelerating the inflammatory responses of gastric tissue infected with $H$. pylori [63] (Figure 3).

\section{IL-32 in Chronic Rhinosinusitis}

Chronic rhinosinusitis (CRS) referred to a diverse inflammatory disease of the nose and paranasal sinuses characterized by at least 12 weeks of two of the following symptoms: hypos$\mathrm{mia} /$ anosmia, nasal obstruction, mucopurulent drainage, and facial pain/pressure [64]. This problem is diagnosed on the basis of clinical history and nasal endoscopy or computed tomography scan is often used to measure inflammation. Chronic rhinosinusitis (CRS) is one of the commonest types of chronic diseases which affects about $15 \%$ of the total population globally. This problem not only stresses healthcare systems by imposing huge financial burdens but also affects the quality of life $[65,66]$. The exact mechanism of pathogenesis involved in the development of CRS is still controversial and is being explored, but a number of factors 
are normally suspected to be involved in the development of this problem, namely, staphylococcal infection as well as cross-linking between its toxins and IgE $[67,68]$. The pathogenesis of this multifaceted inflammatory disorder could be due to genetic and environmental factors [69]. Similarly, several other factors which have been previously reported specifically to be involved in the development of CRS include rhinovirus infections [70], bacterial biofilms [71], and allergic inflammation [72].

CRS with nasal polyps (CRSwNP) and CRS without nasal polyps (CRSsNP) are two common subclasses on the basis of gross endoscopic appearance. Mechanisms of inflammation and symptomatic overlap exist among these two forms while CRSwNP is distinguished as Type 2 helper T [Th2] polarized disease with marked eosinophilia in tissues than CRSsNP (more Type 1 helper T [Th1]) in whites [73].

Keswani et al. (2012) and Soyka et al. (2012) have published two different studies regarding the expression of IL-32 in primary nasal epithelial cells by inflammatory cytokines, namely, TNF- $\alpha$, IFN- $\gamma$, and dsRNA (a TLR3 ligand) which stimulated the upregulation of IL-32 mRNA during CRS. IL$1 \beta$, IL-4, IL-13, IL-17A, IFN- $\beta$, peptidoglycan (a TLR2 ligand), and LPS (a TLR4 ligand) were found to have no effect on the expression of mRNA of IL-32. The presence of IL-32 protein in cell lysates of affected cells and absence in supernatants clearly showed that IL-32 is an endogenous regulator in epithelial cells. The results of both in vitro studies were almost similar and suggested that IL-32 was greatly reproducible as it was found upregulated in airway epithelial cells $[74,75]$.

Immunohistochemical analysis also confirmed the presence of IL-32 in glandular and mucosal epithelium and submucosal inflammatory cells. But no difference was found among the staining intensities of controls and epithelial cells of CRSwNP or CRSsNP [74]. Hence, there is a need for development of a more sensitive assay to detect IL-32 elevation in CRSsNP epithelial cells. Immunohistochemical analysis does not seem to be a sensitive and quantitative approach.

IL-32-positive inflammatory cells were found to be elevated in nasal polyps as well. Colocalization of IL-32 with $\mathrm{CD} 8^{+}$macrophages and $\mathrm{CD}^{+}{ }^{+} \mathrm{T}$-cells was confirmed through immunofluorescence studies which was a clear indicative of positive correlation of its expression with CD3 and macrophage mannose receptor in nasal polyps. These findings showed the involvement of macrophages and T-cells in the production of IL-32 and infiltration of the same cells is responsible for IL-32 elevation in nasal polyps [74]. Presence of IL-32 was reported in some glandular tissues of nasal polyps using immunofluorescent staining though its source was not confirmed as to whether it was coming from unfiltered inflammatory cells or from glandular epithelium [75]. Previously, IL-32 induction has been reported by Th1-related inflammatory cytokines which represents the involvement of IL-32 in Th1-mediated inflammation. However, its enhanced expression, which was characteristically more Th2-mediated type, has also been reported in sinonasal of CRSwNP type $[75,76]$. Similarly, many of Th2-mediated disorders including asthma, allergic rhinitis, atopic dermatitis, and some other diseases have also been linked to IL-32 [77-79]. Severe

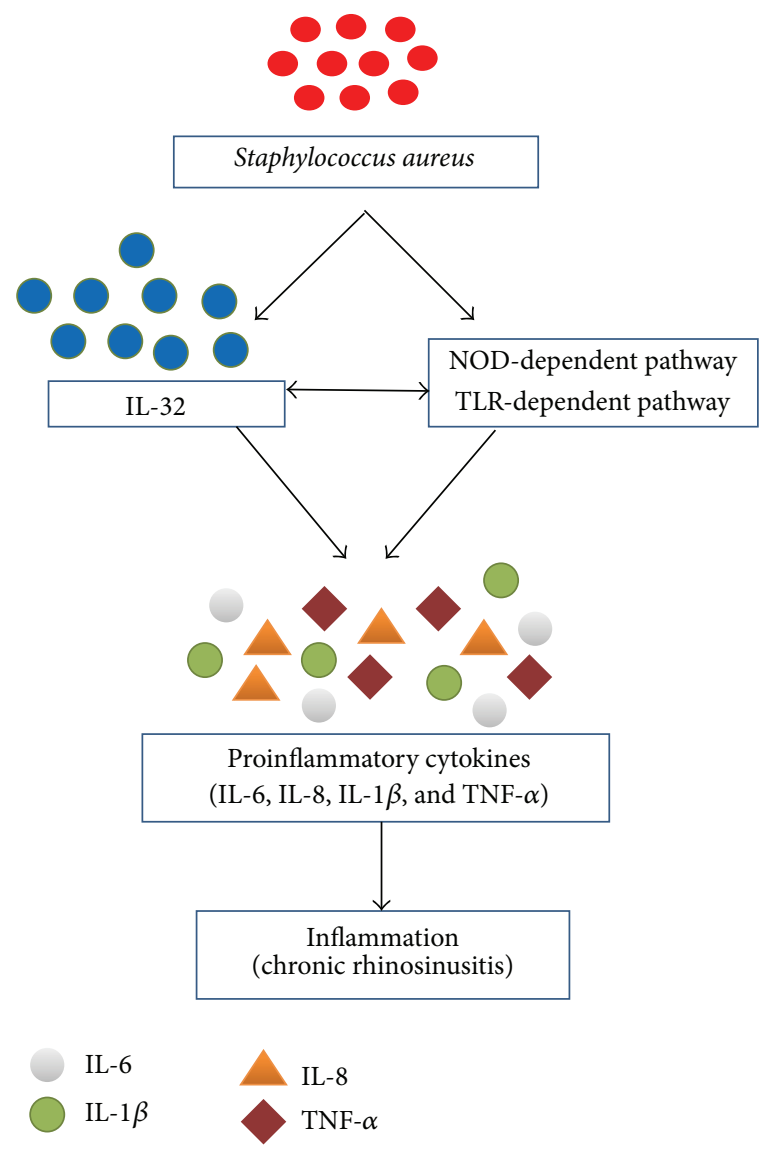

FIgURE 4: Involvement of Staphylococcus aureus in IL-32 induced inflammation in chronic rhinosinusitis. Staphylococcus aureus induces the expression of IL-32 as well as initiating the NODdependent pathway and TLR-dependent pathway which synergistically stimulate the production of some potent proinflammatory cytokines that results in inflammation of chronic rhinosinusitis.

forms of these disorders are also related to Th1 and Th2 inflammation as well $[80,81]$.

IL-32 plays a prime role in the progression of CRS because of its dual property of not only acting as a proinflammatory cytokine, but also regulating a number of other important cytokines. According to one explanation, amplification of the inflammatory response pathogenesis of CRS infection is IL32 related. Various proinflammatory cytokines, namely, IL6 and IL-8, have been enhanced in synergism with TLR2dependent as well as NOD-dependent pathways in nasal polyps [82-85]. Interestingly, TLR2 and NOD ligands containing Staphylococcus aureus commonly colonize the nasal cavity which has the capability of synergizing with IL-32 in CRSwNP type [67, 82, 86]. IL-32 is even found to be involved in the induction of a large array of inflammatory cytokines including IL-1 $\beta$, IL-6, and IL-8, as well as TNF- $\alpha$ directly which clearly suggests the involvement of IL-32 in the pathogenesis and progression of CRS $[4,26,37,87]$ (Figure 4).

In view of the above discussion, it could be concluded that still there is a need for more intensive research to completely understand the crosstalk between IL-32 and immune system 
but on the basis of the available data it can be concluded that IL-32 may play a role in the progression of inflammatory response observed in case of CRS.

\section{Conclusion}

The role of cytokines towards inflammation and modulation of various infectious diseases is a hot topic today. In conclusion, IL-32 is a key modulator in the pathogenesis of various clinical problems which is mostly induced by IL- 8 and enhances the severity of gastric inflammation, gastric cancer, and chronic rhino sinusitis. It not only contributes in the development of inflammation but also induces the expression of a cascade of some potent inflammatory cytokines. There is a need for further investigations of the different pathways regulated by IL-32 which will in turn allow the identification of potential targets for the prevention and treatment of autoimmune, infectious, and inflammatory diseases.

\section{Competing Interests}

The authors declare no conflict of interests.

\section{Acknowledgments}

The authors are thankful to the Vice Chancellor of the University of the Punjab, Lahore, Pakistan, for providing financial support for the accomplishment of this review.

\section{References}

[1] J. F. Navarro-González and C. Mora-Fernández, "The role of inflammatory cytokines in diabetic nephropathy," Journal of the American Society of Nephrology, vol. 19, no. 3, pp. 433-442, 2008.

[2] C. A. Dinarello, "Proinflammatory cytokines," Chest, vol. 118, no. 2, pp. 503-508, 2000.

[3] P. Chomczynski and N. Sacchi, "The single-step method of RNA isolation by acid guanidinium thiocyanate-phenol-chloroform extraction: twenty-something years on," Nature Protocols, vol. 1, no. 2, pp. 581-585, 2006.

[4] S.-H. Kim, S.-Y. Han, T. Azam, D.-Y. Yoon, and C. A. Dinarello, "Interleukin-32: a cytokine and inducer of TNF $\alpha$," Immunity, vol. 22, no. 1, pp. 131-142, 2005.

[5] W. Li, Y. Liu, M. M. Mukhtar et al., "Activation of interleukin32 pro-inflammatory pathway in response to influenza A virus infection," PLoS ONE, vol. 3, no. 4, Article ID e1985, 2008.

[6] H. Shoda, K. Fujio, Y. Yamaguchi et al., "Interactions between IL-32 and tumor necrosis factor alpha contribute to the exacerbation of immune-inflammatory diseases," Arthritis Research \& Therapy, vol. 8, article R166, 2006.

[7] C. A. Dahl, R. P. Schall, H. He, and J. S. Cairns, "Identification of a novel gene expressed in activated natural killer cells and $\mathrm{T}$ cells," The Journal of Immunology, vol. 148, no. 2, pp. 597-603, 1992.

[8] L. A. B. Joosten, B. Heinhuis, M. G. Netea, and C. A. Dinarello, "Novel insights into the biology of interleukin-32," Cellular and Molecular Life Sciences, vol. 70, no. 20, pp. 3883-3892, 2013.

[9] J.-W. Kang, Y. S. Park, D. H. Lee et al., "Intracellular interaction of interleukin (IL)-32 $\alpha$ with protein kinase $\mathrm{C} \varepsilon(\mathrm{PKC} \varepsilon)$ and
STAT3 protein augments IL-6 production in THP-1 promonocytic cells," The Journal of Biological Chemistry, vol. 287, no. 42, pp. 35556-35564, 2012.

[10] J. W. Kang, Y. S. Park, D. H. Lee et al., "Interleukin-32delta interacts with IL-32beta and inhibits IL-32beta-mediated IL-10 production," FEBS Letters, vol. 587, pp. 3776-3781, 2013.

[11] J.-W. Kang, Y. S. Park, M. S. Kim et al., "Interleukin (IL)$32 \beta$-mediated CCAAT/enhancer-binding protein $\alpha(\mathrm{C} / \mathrm{EBP} \alpha)$ phosphorylation by protein kinase $\mathrm{C} \delta(\mathrm{PKC} \delta)$ abrogates the inhibitory effect of C/EBP $\alpha$ on IL-10 production," The Journal of Biological Chemistry, vol. 288, no. 33, pp. 23650-23658, 2013.

[12] B. Heinhuis, M. G. Netea, W. B. van den Berg, C. A. Dinarello, and L. A. B. Joosten, "Interleukin-32: a predominantly intracellular proinflammatory mediator that controls cell activation and cell death," Cytokine, vol. 60, no. 2, pp. 321-327, 2012.

[13] B. Heinhuis, M. I. Koenders, W. B. van den Berg, M. G. Netea, C. A. Dinarello, and L. A. B. Joosten, "Interleukin 32 (IL32) contains a typical $\alpha$-helix bundle structure that resembles focal adhesion targeting region of focal adhesion kinase-1," The Journal of Biological Chemistry, vol. 287, no. 8, pp. 5733-5743, 2012.

[14] J.-W. Kang, Y. S. Park, D. H. Lee et al., "Interaction network mapping among IL-32 isoforms," Biochimie, vol. 101, no. 1, pp. 248-251, 2014.

[15] S. Kim, "Interleukin-32 in inflammatory autoimmune diseases," Immune Network, vol. 14, no. 3, pp. 123-127, 2014.

[16] Y. Zhou and Y. Zhu, "Important role of the IL-32 inflammatory network in the host response against viral infection," Viruses, vol. 7, no. 6, pp. 3116-3129, 2015.

[17] C. Goda, T. Kanaji, S. Kanaji et al., "Involvement of IL32 in activation-induced cell death in T cells," International Immunology, vol. 18, no. 2, pp. 233-240, 2006.

[18] J. I. Chae, J. H. Shim, K. S. Lee et al., "Downregulation of immune response by the human cytokines Interleukin-32 $\alpha$ and $\beta$ in cell-mediated rejection," Cellular Immunology, vol. 264, no. 1, pp. 47-53, 2010.

[19] D. H. Lee, J. E. Hong, H.-M. Yun et al., "Interleukin-32 $\beta$ ameliorates metabolic disorder and liver damage in mice fed high-fat diet," Obesity, vol. 23, no. 3, pp. 615-622, 2015.

[20] S. J. Kim, S. Lee, A. Kwak et al., "Interleukin-32 $\gamma$ transgenic mice resist LPS-mediated septic shock," Journal of Microbiology and Biotechnology, vol. 24, no. 8, pp. 1133-1142, 2014.

[21] K. S. Cho, S. H. Park, S. H. Joo, S.-H. Kim, and C. Y. Shin, "The effects of IL-32 on the inflammatory activation of cultured rat primary astrocytes," Biochemical and Biophysical Research Communications, vol. 402, no. 1, pp. 48-53, 2010.

[22] W. Li, W. Sun, L. Liu et al., "IL-32: a host proinflammatory factor against influenza viral replication is upregulated by aberrant epigenetic modifications during influenza A virus infection," The Journal of Immunology, vol. 185, no. 9, pp. 5056-5065, 2010.

[23] M. F. Nold, C. A. Nold-Petry, G. B. Pott et al., "Endogenous IL-32 controls cytokine and HIV-1 production," The Journal of Immunology, vol. 181, no. 1, pp. 557-565, 2008.

[24] S. T. Rasool, H. Tang, J. Wu et al., "Increased level of IL-32 during human immunodeficiency virus infection suppresses HIV replication," Immunology Letters, vol. 117, no. 2, pp. 161-167, 2008.

[25] J. A. Zepp, C. A. Nold-Petry, C. A. Dinarello, and M. F. Nold, "Protection from RNA and DNA viruses by IL-32," The Journal of Immunology, vol. 186, no. 7, pp. 4110-4118, 2011. 
[26] C. A. Nold-Petry, M. F. Nold, J. A. Zepp, S.-H. Kim, N. F. Voelkel, and C. A. Dinarello, "IL-32-dependent effects of IL$1 \beta$ on endothelial cell functions," Proceedings of the National Academy of Sciences of the United States of America, vol. 106, no. 10, pp. 3883-3888, 2009.

[27] Y. Bak, J. W. Kang, M. S. Kim et al., "IL-32 $\theta$ downregulates CCL5 expression through its interaction with PKCdelta and STAT3," Cellular Signalling, vol. 26, no. 12, pp. 3007-3015, 2014.

[28] M. S. Kim, J. W. Kang, D. H. Lee et al., "IL-32theta negatively regulates IL-1beta production through its interaction with PKCdelta and the inhibition of PU.1 phosphorylation," FEBS Letters, vol. 588, pp. 2822-2829, 2014.

[29] M. S. Kim, J. W. Kang, J. S. Jeon et al., "IL-32theta gene expression in acute myeloid leukemia suppresses TNF-alpha production," Oncotarget, vol. 6, pp. 40747-40761, 2015.

[30] Y. Bak, T. Kwon, I. S. Bak, J. Hong, D. Y. Yu, and D. Y. Yoon, "IL$32 \theta$ inhibits stemness and epithelial-mesenchymal transition of cancer stem cells via the STAT3 pathway in colon cancer," Oncotarget, vol. 7, no. 6, pp. 7307-7317, 2016.

[31] H. Hasegawa, H. J. Thomas, K. Schooley, and T. L. Born, "Native IL-32 is released from intestinal epithelial cells via a nonclassical secretory pathway as a membrane-associated protein," Cytokine, vol. 53, no. 1, pp. 74-83, 2011.

[32] N. Meyer, M. Zimmermann, S. Bürgler et al., "IL-32 is expressed by human primary keratinocytes and modulates keratinocyte apoptosis in atopic dermatitis," Journal of Allergy and Clinical Immunology, vol. 125, no. 4, pp. 858-865.e10, 2010.

[33] M. Schenk, S. R. Krutzik, P. A. Sieling et al., "NOD2 triggers an interleukin-32-dependent human dendritic cell program in leprosy," Nature Medicine, vol. 18, no. 4, pp. 555-563, 2012.

[34] M. Shioya, A. Nishida, Y. Yagi et al., "Epithelial overexpression of interleukin-32 $\alpha$ in inflammatory bowel disease," Clinical and Experimental Immunology, vol. 149, no. 3, pp. 480-486, 2007.

[35] M. G. Netea, E. C. Lewis, T. Azam et al., "Interleukin-32 induces the differentiation of monocytes into macrophage-like cells," Proceedings of the National Academy of Sciences of the United States of America, vol. 105, no. 9, pp. 3515-3520, 2008.

[36] M. Saetta, S. Baraldo, L. Corbino et al., "CD8+ve cells in the lungs of smokers with chronic obstructive pulmonary disease," American Journal of Respiratory and Critical Care Medicine, vol. 160, no. 2, pp. 711-717, 1999.

[37] M. G. Netea, T. Azam, G. Ferwerda et al., "IL-32 synergizes with nucleotide oligomerization domain (NOD) 1 and NOD2 ligands for IL-1 $\beta$ and IL-6 production through a caspase 1-dependent mechanism," Proceedings of the National Academy of Sciences of the United States of America, vol. 102, no. 45, pp. 16309-16314, 2005.

[38] E. Marian, S. Baraldo, A. Visentin et al., "Up-regulated membrane and nuclear leukotriene B4 receptors in COPD," Chest, vol. 129, no. 6, pp. 1523-1530, 2006.

[39] Y.-G. Kim, C.-K. Lee, J. S. Oh, S.-H. Kim, K.-A. Kim, and B. Yoo, "Effect of interleukin-32 $\gamma$ on differentiation of osteoclasts from CD14+ monocytes," Arthritis \& Rheumatism, vol. 62, no. 2, pp. 515-523, 2010.

[40] G. Mabilleau and A. Sabokbar, "Interleukin-32 promotes osteoclast differentiation but not osteoclast activation," PLoS ONE, vol. 4, no. 1, Article ID e4173, 2009.

[41] B. Heinhuis, M. I. Koenders, P. L. Van Riel et al., "Tumour necrosis factor alpha-driven IL-32 expression in rheumatoid arthritis synovial tissue amplifies an inflammatory cascade," Annals of the Rheumatic Diseases, vol. 70, no. 4, pp. 660-667, 2011.
[42] B. Heinhuis, M. I. Koenders, F. A. van de Loo, M. G. Netea, W. B. van den Berg, and L. A. B. Joosten, "Inflammationdependent secretion and splicing of IL-32 $\gamma$ in rheumatoid arthritis," Proceedings of the National Academy of Sciences of the United States of America, vol. 108, no. 12, pp. 4962-4967, 2011.

[43] J.-W. Kang, S.-C. Choi, M.-C. Cho et al., "A proinflammatory cytokine interleukin-32 $\beta$ promotes the production of an antiinflammatory cytokine interleukin-10," Immunology, vol. 128, no. 1, pp. e532-e540, 2009.

[44] B. Khawar, M. H. Abbasi, and N. Sheikh, "A panoramic spectrum of complex interplay between the immune system and IL-32 during pathogenesis of various systemic infections and inflammation," European Journal of Medical Research, vol. 20, article 7, 2015.

[45] A. Jemal, R. Siegel, E. Ward et al., "Cancer statistics, 2008," CA Cancer Journal for Clinicians, vol. 58, no. 2, pp. 71-96, 2008.

[46] C.-Y. Tsai, C.-S. Wang, M.-M. Tsai et al., "Interleukin-32 increases human gastric cancer cell invasion associated with tumor progression and metastasis," Clinical Cancer Research, vol. 20, no. 9, pp. 2276-2288, 2014.

[47] H. Tsujimoto, S. Ono, T. Ichikura, Y. Matsumoto, J. Yamamoto, and K. Hase, "Roles of inflammatory cytokines in the progression of gastric cancer: friends or foes?" Gastric Cancer, vol. 13, no. 4, pp. 212-221, 2010.

[48] E.-H. Seo, J. Kang, K.-H. Kim et al., "Detection of expressed IL32 in human stomach cancer using ELISA and immunostaining," Journal of Microbiology and Biotechnology, vol. 18, no. 9, pp. 1606-1612, 2008.

[49] T. L. Naylor, J. Greshock, Y. Wang et al., "High resolution genomic analysis of sporadic breast cancer using array-based comparative genomic hybridization," Breast Cancer Research, vol. 7, no. 6, pp. R1186-R1198, 2005.

[50] B. Diosdado, T. E. Buffart, R. Watkins et al., "High-resolution array comparative genomic hybridization in sporadic and celiac disease-related small bowel adenocarcinomas," Clinical Cancer Research, vol. 16, no. 5, pp. 1391-1401, 2010.

[51] J. Robin Warren and B. Marshall, "Unidentified curved bacilli on gastric epithelium in active chronic gastritis," The Lancet, vol. 321, no. 8336, pp. 1273-1275, 1983.

[52] N. Uemura, S. Okamoto, S. Yamamoto et al., "Helicobacter pylori infection and the development of gastric cancer," The New England Journal of Medicine, vol. 345, no. 11, pp. 784-789, 2001.

[53] K. Sakitani, Y. Hirata, H. Watabe et al., "Gastric cancer risk according to the distribution of intestinal metaplasia and neutrophil infiltration," Journal of Gastroenterology and Hepatology, vol. 26, no. 10, pp. 1570-1575, 2011.

[54] A. C. de Vries, N. C. T. van Grieken, C. W. N. Looman et al., "Gastric cancer risk in patients with premalignant gastric lesions: a nationwide cohort study in the Netherlands," Gastroenterology, vol. 134, no. 4, pp. 945-952, 2008.

[55] S. Maeda and A. F. Mentis, "Pathogenesis of Helicobacter pylori infection," Helicobacter, vol. 12, no. 1, pp. 10-14, 2007.

[56] T. Ohmae, Y. Hirata, S. Maeda et al., "Helicobacter pylori activates NF- $\kappa \mathrm{B}$ via the alternative pathway in B lymphocytes," The Journal of Immunology, vol. 175, no. 11, pp. 7162-7169, 2005.

[57] K. Ogura, M. Takahashi, S. Maeda et al., "Interleukin-8 production in primary cultures of human gastric epithelial cells induced by Helicobacter pylori," Digestive Diseases and Sciences, vol. 43, no. 12, pp. 2738-2743, 1998.

[58] M. Suzuki, M. Mori, A. Miyayama et al., "Enhancement of neutrophil infiltration in the corpus after failure of Helicobacter 
pylori eradication," Journal of Clinical Gastroenterology, vol. 25, no. 1, pp. S222-S228, 1997.

[59] J. E. Crabtree, A. Covacci, S. M. Farmery et al., "Helicobacter pylori induced interleukin-8 expression in gastric epithelial cells is associated with CagA positive phenotype," Journal of Clinical Pathology, vol. 48, no. 1, pp. 41-45, 1995.

[60] A. Taguchi, N. Ohmiya, K. Shirai et al., "Interleukin-8 promoter polymorphism increases the risk of atrophic gastritis and gastric cancer in Japan," Cancer Epidemiology Biomarkers and Prevention, vol. 14, no. 11 I, pp. 2487-2493, 2005.

[61] M. Sugimoto, T. Furuta, N. Shirai et al., "Different effects of polymorphisms of tumor necrosis factor-alpha and interleukin1 beta on development of peptic ulcer and gastric cancer," Journal of Gastroenterology and Hepatology, vol. 22, no. 1, pp. 51-59, 2007.

[62] E. M. El-Omar, M. Carrington, W.-H. Chow et al., "Interleukin1 polymorphisms associated with increased risk of gastric cancer," Nature, vol. 404, no. 6776, pp. 398-402, 2000.

[63] K. Sakitani, Y. Hirata, Y. Hayakawa et al., "Role of interleukin-32 in Helicobacter pylori-induced gastric inflammation," Infection and Immunity, vol. 80, no. 11, pp. 3795-3803, 2012.

[64] E. O. Meltzer and D. L. Hamilos, "Rhinosinusitis diagnosis and management for the clinician: a synopsis of recent consensus guidelines," Mayo Clinic Proceedings, vol. 86, no. 5, pp. 427-443, 2011.

[65] W. Fokkens, V. Lund, and J. Mullol, "EP ${ }^{3} \mathrm{OS}$ 2007: European position paper on rhinosinusitis and nasal polyps 2007. A summary for otorhinolaryngologists," Rhinology, vol. 45, pp. 97-101, 2007.

[66] P. Van Cauwenberge and J. B. Watelet, "Epidemiology of chronic rhinosinusitis," Thorax, vol. 55, supplement 2, pp. S20-S21, 2000.

[67] T. Van Zele, P. Gevaert, J.-B. Watelet et al., "Staphylococcus aureus colonization and IgE antibody formation to enterotoxins is increased in nasal polyposis," Journal of Allergy and Clinical Immunology, vol. 114, no. 4, pp. 981-983, 2004.

[68] F. Sachse, K. Becker, C. Von Eiff, D. Metze, and C. Rudack, "Staphylococcus aureus invades the epithelium in nasal polyposis and induces IL-6 in nasal epithelial cells in vitro," Allergy, vol. 65, no. 11, pp. 1430-1437, 2010.

[69] L. Mfuna-Endam, Y. Zhang, and M. Y. Desrosiers, "Genetics of rhinosinusitis," Current Allergy and Asthma Reports, vol. 11, no. 3, pp. 236-246, 2011.

[70] Y. J. Jang, H.-J. Kwon, H.-W. Park, and B.-J. Lee, "Detection of rhinovirus in turbinate epithelial cells of chronic sinusitis," American Journal of Rhinology, vol. 20, no. 6, pp. 634-636, 2006.

[71] J. D. Suh, N. A. Cohen, and J. N. Palmer, "Biofilms in chronic rhinosinusitis," Current Opinion in Otolaryngology \& Head and Neck Surgery, vol. 18, no. 1, pp. 27-31, 2010.

[72] D. L. Hamilos, D. Y. M. Leung, R. Wood et al., "Evidence for distinct cytokine expression in allergic versus nonallergic chronic sinusitis," The Journal of Allergy and Clinical Immunology, vol. 96, no. 4, pp. 537-544, 1995.

[73] W. Huvenne, N. van Bruaene, N. Zhang et al., "Chronic rhinosinusitis with and without nasal polyps: what is the difference?" Current Allergy and Asthma Reports, vol. 9, no. 3, pp. 213-220, 2009.

[74] A. Keswani, R. T. Chustz, L. Suh et al., "Differential expression of interleukin-32 in chronic rhinosinusitis with and without nasal polyps," Allergy, vol. 67, no. 1, pp. 25-32, 2012.
[75] M. B. Soyka, A. Treis, T. Eiwegger et al., "Regulation and expression of IL-32 in chronic rhinosinusitis," Allergy, vol. 67, no. 6, pp. 790-798, 2012.

[76] A. Keswani, R. C. Kern, R. P. Schleimer, and A. Kato, "Role of interleukin-32 in chronic rhinosinusitis," Current Opinion in Allergy and Clinical Immunology, vol. 13, no. 1, pp. 13-18, 2013.

[77] N. Meyer, M. Zimmermann, S. Bürgler et al., "IL-32 is expressed by human primary keratinocytes and modulates keratinocyte apoptosis in atopic dermatitis," Journal of Allergy and Clinical Immunology, vol. 125, no. 4, pp. 858.e10-865.e10, 2010.

[78] N. Meyer, J. Christoph, H. Makrinioti et al., "Inhibition of angiogenesis by IL-32: possible role in asthma," Journal of Allergy and Clinical Immunology, vol. 129, no. 4, pp. 964-973.e7, 2012.

[79] H.-J. Jeong, S.-Y. Shin, H.-A. Oh, M.-H. Kim, J.-S. Cho, and H.M. Kim, "IL-32 up-regulation is associated with inflammatory cytokine production in allergic rhinitis," The Journal of Pathology, vol. 224, no. 4, pp. 553-563, 2011.

[80] P. M. Hansbro, G. E. Kaiko, and P. S. Foster, "Cytokine/anticytokine therapy—novel treatments for asthma?" British Journal of Pharmacology, vol. 163, no. 1, pp. 81-95, 2011.

[81] K.-I. Yamanaka and H. Mizutani, "The role of cytokines/chemokines in the pathogenesis of atopic dermatitis," Current Problems in Dermatology, vol. 41, pp. 80-92, 2011.

[82] B. Heinhuis, M. I. Koenders, F. A. van de Loo et al., "IL-32 $\gamma$ and Streptococcus pyogenes cell wall fragments synergise for IL1-dependent destructive arthritis via upregulation of TLR-2 and NOD2," Annals of the Rheumatic Diseases, vol. 69, no. 10, pp. 1866-1872, 2010.

[83] A. T. Peters, A. Kato, N. Zhang et al., "Evidence for altered activity of the IL-6 pathway in chronic rhinosinusitis with nasal polyps," The Journal of Allergy and Clinical Immunology, vol. 125, no. 2, pp. 397.e10-403.e10, 2010.

[84] H. Riechelmann, T. Deutschle, A. Rozsasi, T. Keck, D. Polzehl, and H. Bürner, "Nasal biomarker profiles in acute and chronic rhinosinusitis," Clinical and Experimental Allergy, vol. 35, no. 9, pp. 1186-1191, 2005.

[85] M. G. Netea, T. Azam, G. Ferwerda et al., "IL-32 synergizes with nucleotide oligomerization domain (NOD) 1 and NOD2 ligands for IL-1 $\beta$ and IL-6 production through a caspase 1-dependent mechanism," Proceedings of the National Academy of Sciences of the United States of America, vol. 102, no. 45, pp. 16309-16314, 2005.

[86] Y. Sun, B. Zhou, C. Wang et al., "Biofilm formation and Toll-like receptor 2, Toll-like receptor 4 , and NF-kappaB expression in sinus tissues of patients with chronic rhinosinusitis," American Journal of Rhinology and Allergy, vol. 26, no. 2, pp. 104-109, 2012.

[87] J. Hong, S. Bae, Y. Kang et al., "Suppressing IL-32 in monocytes impairs the induction of the proinflammatory cytokines TNF $\alpha$ and IL-1 $\beta$," Cytokine, vol. 49, no. 2, pp. 171-176, 2010. 


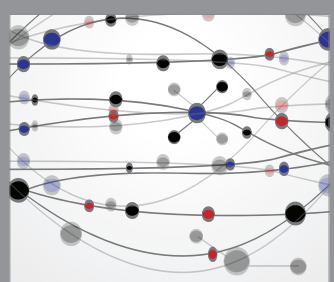

The Scientific World Journal
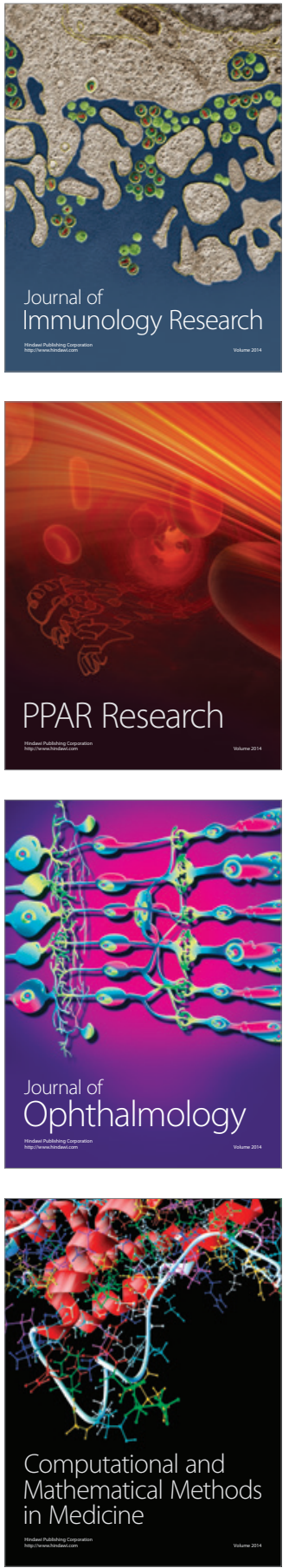

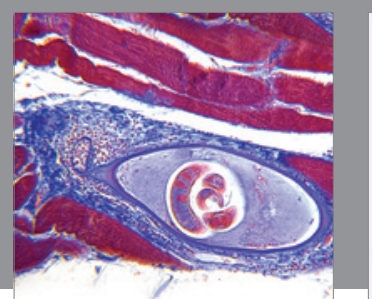

Gastroenterology Research and Practice

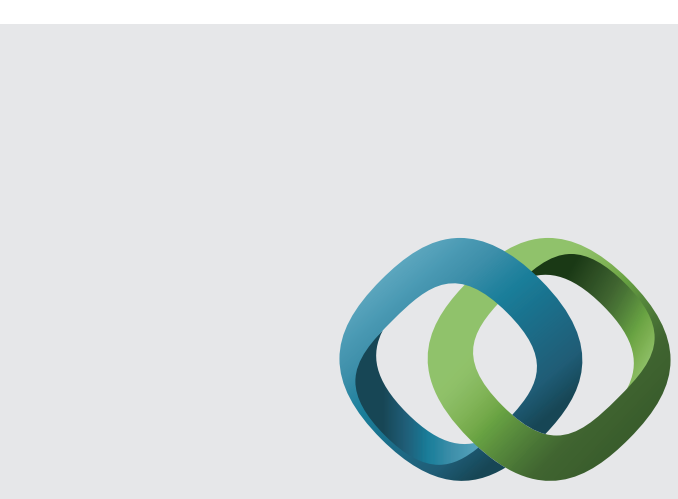

\section{Hindawi}

Submit your manuscripts at

http://www.hindawi.com
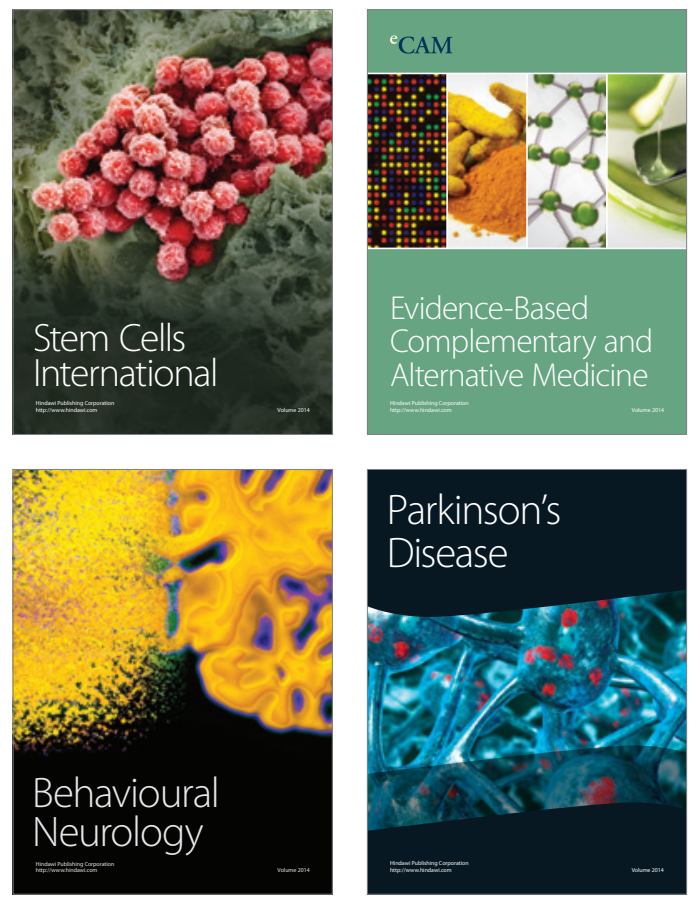
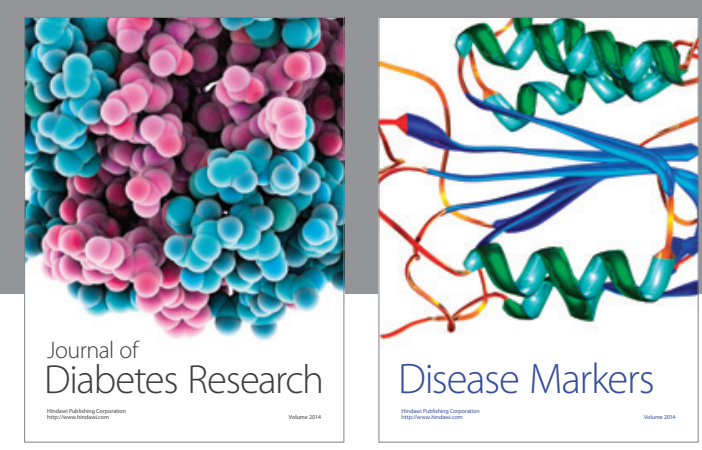

Disease Markers
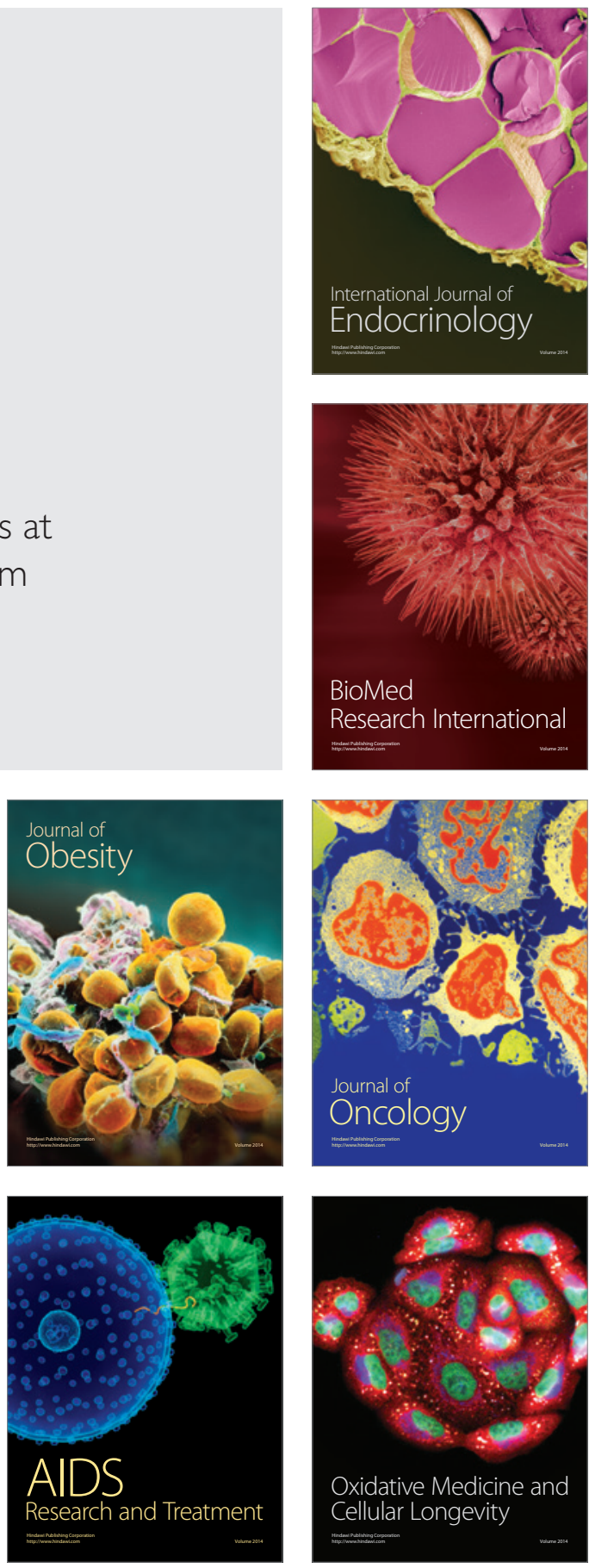